\title{
Association of Fibrinogen, Erythrocyte Sedimentation Rate and C-Reactive Protein Levels with Rheumatoid Arthritis
}

\author{
Mohamed Babikir Omer Babikir, Nasr Eldeen Ali Mohammed Gaufri* \\ Department of Hematology, Faculty of Medical Laboratory Sciences, Alneelain University, Khartoum, Sudan \\ Email: ${ }^{*}$ Nasralimohammed@yahoo.com
}

How to cite this paper: Babikir, M.B.O. and Gaufri, N.E.A.M. (2017) Association of Fibrinogen, Erythrocyte Sedimentation Rate and C-Reactive Protein Levels with Rheumatoid Arthritis. Open Access Library Journal, 4: e3430.

https://doi.org/10.4236/oalib.1103430

Received: February 4, 2017

Accepted: April 9, 2017

Published: April 12, 2017

Copyright $\odot 2017$ by authors and Open Access Library Inc.

This work is licensed under the Creative Commons Attribution International License (CC BY 4.0).

http://creativecommons.org/licenses/by/4.0/

\begin{abstract}
Background: Many studies were made the association between the extent of the inflammatory response, increase fibrinogen level and hypercoagulability in rheumatoid arthritis. The current study aims to the investigation and finds the association of the fibrinogen, ESR and CRP levels in Sudanese patients with rheumatoid arthritis. Material and Methods: This is a case-control study, conducted at Modern Medical Center, Khartoum, Sudan, during January 2016. Totally 100 participants were chosen for this study, among them 50 were known Sudanese patients professionally diagnosed with rheumatoid arthritis as case group, and the other 50 participants were normal healthy subjects as control group; their age and gender coordinated with case group. 3 $\mathrm{ml}$ of blood was collected in Tri Sodium citrate container, and other $3 \mathrm{ml}$ in plain container. Platelet poor plasma prepared by centrifugation of tri sodium citrate container, and then plasma separated to estimate fibrinogen. Serum was prepared form clotted blood to measure CRP. The ESR was done by Westergren tube from citrated blood in one hour. The data were collected by structured interview and questionnaire, and then analyzed by using a computer program statistical package for social sciences (SPSS) version 20. Results: Significant elevated of the plasma fibrinogen, CRP levels and ESR were observed in subjects with rheumatoid arthritis in comparison with that normal control group with ( $\mathrm{p}$ value 0.000 ). Conclusion: This study has shown that rheumatoid arthritis lead to increase level of fibrinogen, ESR and CRP. This abnormality could be contributed to the hypercoagulability phenomenon.
\end{abstract}

\section{Subject Areas}

Hematology 


\section{Keywords}

Rheumatoid Arthritis, Fibrinogen, C-Reactive Protein, Erythrocyte

Sedimentation Rate, Sudan

\section{Introduction}

Rheumatoid arthritis is a long lasting autoimmune disorder that primarily affects joints. It typically results in warm, swollen, and painful joints. Pain and stiffness often worsen following rest. Most commonly the wrist and hands are involved with typically the same joints involved on both sides of the body. The disease may also affect other parts of the body. This may result in low red blood cells, inflammation around the lungs, and inflammation around the heart. Fever and low energy may also be present [1] [2]. While the cause of rheumatoid arthritis is not clear, it is believed to involve a combination of genetic and environmental factors. X-rays and laboratory testing may support a diagnosis or exclude other diseases with similar symptoms [2]. Other diseases that may present similarly include systemic lupus erythematosis, psoriatic arthritis, and fibromyalgia among others [2]. Women are affected three to five times as often as men [3]. The age at which the disease most commonly starts is in women between 40 and 50 years of age, and for men somewhat later [4]. When RA is clinically suspected, testing for the presence of rheumatoid factor (RF, a non-specific antibody) and anticitrulated proteins antibodies (ACPAs) may be required [5]. Also, several other blood tests are usually done to allow for other causes of arthritis, such as lupus erythematosus. The erythrocyte sedimentation rate (ESR), C-reactive protein, full blood count, kidney function, liver enzymes and other immunological tests (e.g., antinuclear antibody/ANA) are all performed at this stage [5]. Acute phase reactants (APRs), such as serum C-reactive protein (CRP), plasma fibrinogen, and ESR are common biomarkers used to monitor the status of inflammatory diseases. The acute-phase response to tissue injury and inflammation is accompanied by a dramatic increase in hepatic synthesis of acute-phase reactants (APR). Therefore, characterization of APR responses in RA is essential to gain insights into the activity of this disease and to assess the degree of inflammation. Both CRP and ESR levels are used to monitor disease activity and to monitor how well someone is responding to treatment [6] [7]. Fibrinogen (factor I) is a glycoprotein that helps in the formation of blood clots [8]. The fibrinogen molecule is a soluble, large plasma glycoprotein that is converted by thrombin into fibrin during blood clot formation [3]. Fibrinogen is synthesized in the liver by the hepatocytes [9]. Research from 2011 has shown that fibrin plays a key role in the inflammatory response and development of rheumatoid arthritis [10]. Fibrinogen levels can be measured in venous blood. Normal levels are about $2.0-4.0 \mathrm{~g} / \mathrm{L}$, depending on the method used. In typical circumstances, fibrinogen is measured in citrated plasma samples in the laboratory, however the analysis of whole-blood samples by use of thromboelastometry (platelet function 
is inhibited with cytochalasin D) is also possible [11]. Higher levels are, associated with inflammation, as it is an acute-phase protein [12]. Fibrinogen level used as an inflammatory marker [13]. There is ample evidence to suggest increased clotting potential in RA patients. Elevated fibrinogen, von willebr- and factor, fibrin D-dimer, and tissue plasminogen activator antigen concentrations are seen in RA patients, even in those with well-controlled RA [14]. Further contributing to a hypercoagulable state in RA is the thrombocytosis [15]. Many of these parameters are clearly associated with the extent of the inflammatory response, and explanatory mechanisms are evident. For example, TNF causes the expression of tissue factor on monocytes and possibly endothelium, thereby initiating the coagulation cascade, whereas IL-6 can increase levels of fibrinogen, an acute-phase reactant [16].

\section{Materials and Method}

This is a case-control study, conducted during January 2016 at Faculty of Medical Laboratory Sciences, Alneelain University, Khartoum, Sudan. A total of 100 participants were selected for this study, 50 (20) male and (30) female was patients professionally diagnosed by rheumatoid arthritis according to blood tests for rheumatoid factor and anti-cyclic citrullinated peptide (anti-CCP) antibodies and present of Clinical presentation admitted to the Modern Medical Center; their age their mean age was 39 years are designated as case group. Other 50 participants (17) male and (33) female was normal healthy subjects designated as control group; their gender and age were matched with patient group. $6 \mathrm{ml}$ of blood was drawn from all subjects; $3 \mathrm{ml}$ in containers contain trisodium citrate as anticoagulant, and other $3 \mathrm{ml}$ of blood in plain container. The platelet poor plasma was prepared immediately by centrifugation at $2000 \mathrm{rpm}$ for 15 minutes at $4 \mathrm{c}$ for measuring fibrinogen level, while the serum was prepared from plain container to measure Anti-CCP, RF and CRP. Plasma fibrinogen level was determined with a commercial kit using an automated analyzer (thrombolayzerJapan).The ESR was done by westergren method. Anti-CCP was measured by using ELISA kits Euroimmune (Germany).Rheumatoid factor and CRP were measured by turbidometeric method using automated chemistry analyzer (Mindray 480-China).Every patient with autoimmune disease, history of coagulopathy disorders, pregnancy or has other inflammation were excluded from this study. This study was approved from Alneelain University, Faculty of Medical Laboratory ethical committee, and the approval consent also was taken from all participants before the samples were collected. Data was collected by direct questionnaire then computed and analyzed by using a computer program statistical package for social sciences (SPSS) version 20. T.test was used to compare between the parameters and correlation between variables was assessed by using Pearson test. The significant of p.value was set less than 0.05

\section{Results}

A total of 100 subjects were enrolled in this study, 50 of them were known Su- 
danese patients diagnosed by rheumatoid arthritis found male $20(40 \%)$ and female $30(60 \%)$, and the age of patients was ranged from 31 - 47 years. Further 50 normal healthy adult as control group. The age of control group was matched with patients group.

The present study showed that the Fibrinogen, CRP, Anti-CCP, ESR levels and rheumatoid factor were statistically significantly higher in patients with rheumatoid arthritis compared with normal health control group with $\mathrm{P}$ value 0.000 (Table 1).

The analysis of this study revealed that there is strong positive correlation between Anti-CCP and ESR (P-value 0.002) (Table 2).

This study found that there is statistically significant correlation between rheumatoid factor and ESR level (P value 0.009) while there is no correlation between fibrinogen level, CRP and rheumatoid factor with (P-value 0.817 and 0.577 ) respectively (Table 3 ).

Table 4 showed that there is statistically significantly correlation between duration of the disease and fibrinogen level and ESR with (P value 0.043 and 0.044 ) respectively.

Based on age this study found there is statistically significantly correlation between age and fibrinogen level and ESR (P-value 0.029) (P-value 0.027) respectively, and insignificant correlation between age of the patient and CRP ( $P$-value 0.114) (Table 5).

\section{Discussion}

RA is a systemic inflammation associated with increased the risk of cardiovascular (CV) events, including thrombosis, levels of fibrinogen, a pro-thrombotic

Table 1. Association of Fibrinogen level, CRP, Anti-CCP, ESR and rheumatoid factor with rheumatoid arthritis among case and control group.

\begin{tabular}{ccccc}
\hline Parameters & Number & Case $($ Mean \pm SD) & Control (Mean \pm SD) & P-value \\
\hline Fibrinogen level mg/dL & 50 & $347.92 \pm 53.78$ & $228.22 \pm 19.55$ & 0.000 \\
CRP mg/L & 50 & $22.62 \pm 14.77$ & $3.36 \pm 1.54$ & 0.000 \\
Anti-CCP IU/mL & 50 & $14.76 \pm 12.09$ & $1.02 \pm 0.71$ & 0.000 \\
ESR mm/hour & 50 & $58.00 \pm 30.96$ & $7.68 \pm 4.37$ & 0.000 \\
R.Factor IU/mL & $\mathbf{5 0}$ & $35.52 \pm 22.58$ & $8.78 \pm 4.21$ & 0.000 \\
\hline
\end{tabular}

CRP: C-reactive protien, Anti-CCP: anticitrulated proteins, ESR: erythrocyte sedimentation rate, RF: rhuematoid factor.

Table 2. Correlation between Anti-CCP and fibrinogen level, CRP and ESR.

\begin{tabular}{ccc}
\hline Parameters & R-value & P-value \\
\hline Fibrinogen level & 0.139 & 0.335 \\
CRP & 0.086 & 0.553 \\
ESR & 0.430 & 0.002 \\
\hline
\end{tabular}

CRP: C-reactive protien, ACCP: anticitrulated proteins, ESR: erythrocyte sedimentation rate. 
Table 3. Correlation between rheumatoid factor and fibrinogen level, CRP and ESR.

\begin{tabular}{ccc}
\hline Parameters & R-value & P-value \\
\hline Fibrinogen level & 0.039 & 0.817 \\
CRP & 0.081 & 0.577 \\
ESR & 0.360 & 0.009 \\
\hline
\end{tabular}

CRP: C-reactive protien, ESR: erythrocyte sedimentation rate.

Table 4. Correlation between duration and fibrinogen level, CRP and ESR.

\begin{tabular}{ccc}
\hline Parameters & R-value & P-value \\
\hline Fibrinogen level & 0.287 & 0.043 \\
CRP & 0.069 & 0.636 \\
ESR & 0.247 & 0.044 \\
\hline
\end{tabular}

CRP: C-reactive protein, ESR: erythrocytes sedimentation rate.

Table 5. Correlation between age and fibrinogen level, CRP and ESR.

\begin{tabular}{ccc}
\hline Parameters & R-value & P-value \\
\hline Fibrinogen level & 0.309 & 0.029 \\
CRP & 0.226 & 0.114 \\
ESR & 0.313 & 0.027 \\
\hline
\end{tabular}

CRP: C-reactive protein, ESR: erythrocytes sedimentation rate.

protein with predictive value for $\mathrm{CV}$ disease (CVD), are elevated during rheumatoid arthritis [17]. Recently mortality rate of Rheumatoid arthritis (RA) was dramatically increased (standardized mortality rate 1.4 - 3.0) [18] [19] and fifty percent of deaths were due to cardiovascular disease [20] [21] [22]. It is prevalence in rural Africa around 1\% of the population [22] [23]. The literature suggests that there is an association between fibrinogen, erythrocyte sedimentation rate (ESR) and serum C-reactive protein (CRP) levels in rheumatoid arthritis patients. This study aimed to the measurement the fibrinogen, CRP and ESR levels in Sudanese rheumatoid arthritis patients. The current study showed that the plasma fibrinogen, CRP and ESR levels were statistically significant higher in rheumatoid arthritis patients compared with normal healthy control group $($ Mean \pm SD $347.92 \pm 53.78 \mathrm{mg} / \mathrm{dl}$ ), elevated CRP level (Mean \pm SD $22.62 \pm$ 14.77) and elevated ESR (Mean \pm SD $58.00 \pm 30.96$ with P value 0.000 ) respectively. This finding was in agreement with study done by Terence Rooney et al. (2011) in San Francisco, CA, USA who demonstrate 105 patients and reported that fibrinogen, CRP and ESR levels were significantly higher [17]. Our findings were in concordance with studies (2004) in Turkish [24] and United Kingdom (2001) [14] populations in which it found that the fibrinogen levels were significantly elevated in RA patients. The findings also support the findings of R.T. Keenan et al (2008) in New York, USA who demonstrated ESR and CRP in 188 RA patients and they concluded that the levels were significantly elevated with $\mathrm{P}$ 
value $<0.0001$ [25]. The interesting findings of this study revealed that there is strong positive correlation between Anti-CCP and ESR level, also the positive correlation found between fibrinogen and ESR level with patient age and duration of the disease. This finding emphasizes that the long lasting rheumatoid arthritis patients prone the thrombosis. Based on the gender this study showed that the female more affected by rheumatoid arthritis this findings were in a consistence with several studies done in different countries [4] [26] [27] [28] [29] [30]. The most common limitations in this study that the number of cases and shortage of the study duration.

\section{Conclusion}

According to the findings, this study concluded that: Rheumatoid Arthritis leads to the increased fibrinogen, CRP and ESR levels. There is a significant correlation between fibrinogen level and erythrocytes sedimentation rate with patient age and the duration of the disease. The significant correlation also found between Anti-CCP, rheumatoid factor and ESR.

\section{References}

[1] National Institute of Arthritis and Musculoskeletal and Skin Diseases (2014) Handout on Health: Rheumatoid Arthritis.

[2] Majithia, V. and Geraci, S.A. (2007) Rheumatoid Arthritis: Diagnosis and Management. The American Journal of Medicine, 120, 936-939.

[3] Shah, A. (2011) Harrison's Principle of Internal Medicine. 18th Edition, McGraw Hill, New York, 2738.

[4] Alamanos, Y., Voulgari, P.V. and Drosos, A.A. (2006) Incidence and Prevalence of Rheumatoid Arthritis, Based on the 1987 American College of Rheumatology Criteria: A Systematic Review. Seminars in Arthritis and Rheumatism, 36, 182-188.

[5] Westwood, O.M., Nelson, P.N. and Hay, F.C. (2006) Rheumatoid Factors: What's New? Rheumatology, 45, 379-385. https://doi.org/10.1093/rheumatology/kei228

[6] Pedrazzi, A.H. (1998) Acute Phase Proteins-Clinical and Laboratory Diagnosis. Annales Pharmaceutiques Françaises, 56, 108-114.

[7] Gabay, C. and Kushner, I. (1999) Acute-Phase Proteins and Other Systemic Responses to Inflammation. The New England Journal of Medicine, 340, 448-454. https://doi.org/10.1056/NEJM199902113400607

[8] Marucco, A., Fenoglio, I., Turci, F. and Fubini, B. (2013) Interaction of Fibrinogen and Albumin with Titanium Dioxide Nanoparticles of Different Crystalline Phases. Journal of Physics: Conference Series, 429, Article ID: 012014. https://doi.org/10.1088/1742-6596/429/1/012014

[9] Gilliam, B.E., Reed, M.R., Chauhan, A.K., Dehlendorf, A.B. and Moore, T.L. (2011) Evidence of Fibrinogen as a Target of Citrullination in IgM Rheumatoid FactorPositive Polyarticular Juvenile Idiopathic Arthritis. Pediatric Rheumatology, 9, 8. https://doi.org/10.1186/1546-0096-9-8

[10] Lang, T., Johanning, K., Metzler, H., Piepenbrock, S., Solomon, C., Rahe-Meyer, N. and Tanaka, K.A. (2009) The Effects of Fibrinogen Levels on Thromboelastometric Variables in the Presence of Thrombocytopenia. Anesthesia \& Analgesia, 108, 751758. https://doi.org/10.1213/ane.0b013e3181966675 
[11] Fries, D., Innerhofer, P. and Schobersberger, W. (2009) Time for Changing Coagulation Management in Trauma-Related Massive Bleeding. Current Opinion in Anesthesiology, 22, 267-274. https://doi.org/10.1097/ACO.0b013e32832678d9

[12] Page, R.C. and Schroeder, H.E. (1976) Pathogenesis of Inflammatory Periodontal Disease. A Summary of Current Work. Laboratory Investigation. A Journal of Technical Methods and Pathology, 34, 235-249.

[13] Salvi, V. (2003) Medical and Surgical Diagnostic Disorders in Pregnancy. Jaypee Brothers Publishers, New Delhi, 5. https://doi.org/10.5005/jp/books/11070

[14] McEntegart, A., Capell, H.A., Creran, D., et al. (2001) Cardiovascular Risk Factors, Including Thrombotic Variables, in a Population with Rheumatoid Arthritis. Rheumatology, 40, 640-644. https://doi.org/10.1093/rheumatology/40.6.640

[15] Grignani, G. and Maiolo, A. (2000) Cytokines and Hemostasis. Haematologica, 85, 967-972.

[16] Liuzzo, G., Goronzy, J.J., Yang, H., Kopecky, S.L., Holmes, D.R., Frye, R.L. and Weyand, C.M. (2000) Monoclonal T-Cell Proliferation and Plaque Instability in Acute Coronary Syndromes. Circulation, 101, 2883-2888.

https://doi.org/10.1161/01.CIR.101.25.2883

[17] Rooney, T., Scherzer, R., Shigenaga, J.K., Graf, J., Imboden, J.B. and Grunfeld, C. (2011) Levels of Plasma Fibrinogen Are Elevated in Well-Controlled Rheumatoid Arthritis. Rheumatology, 50, 1458-1465.

https://doi.org/10.1093/rheumatology/ker011

[18] Mutru, O., Laakso, M., Isomäki, H. and Koota, K. (1985) Ten Year Mortality and Causes of Death in Patients with Rheumatoid Arthritis. The British Medical Journal, 290, 1797-1799. https://doi.org/10.1136/bmj.290.6484.1797

[19] Prior, P., Symmons, D.P., Scott, D.L., Brown, R. and Hawkins, C.F. (1984) Cause of Death in Rheumatoid Arthritis. Rheumatology, 23, 92-99.

https://doi.org/10.1093/rheumatology/23.2.92

[20] Myllykangas-Luosujärvi, R., Aho, K., Kautiainen, H. and Isomäki, H. (1995) Cardiovascular Mortality in Women with Rheumatoid Arthritis. The Journal of Rheumatology, 22, 1065-1067.

[21] Wolfe, F., Mitchell, D.M., Sibley, J.T., et al. (1994) The Mortality of Rheumatoid Arthritis. Arthritis \& Rheumatology, 37, 481-494. https://doi.org/10.1002/art.1780370408

[22] Spector, T.D., Hart, D.J. and Powell, R.J. (1993) Prevalence of Rheumatoid Arthritis and Rheumatoid Factor in Women: Evidence for a Secular Decline. Annals of the Rheumatic Diseases, 52, 254-257. https://doi.org/10.1136/ard.52.4.254

[23] Peschken, C.A. and Esdaile, J.M. (1999) Rheumatic Diseases in North America's Indigenous Peoples. Seminars in Arthritis and Rheumatism, 28, 368-391.

[24] Yildirim, K., Karatay, S., Melikoglu, M.A., Gureser, G., Ugur, M. and Senel, K. (2004) Associations between Acute Phase Reactant Levels and Disease Activity Score (DAS28) in Patients with Rheumatoid Arthritis. Annals of Clinical \& Laboratory Science, 34, 423-426.

[25] Keenan, R.T., Swearingen, C.J. and Yazici, Y. (2008) Erythrocyte Sedimentation Rate and C-Reactive Protein Levels Are Poorly Correlated with Clinical Measures of Disease Activity in Rheumatoid Arthritis, Systemic Lupus Erythematosus and Osteoarthritis Patients. Clinical \& Experimental Rheumatology, 26, 814.

[26] Forslind, K., Hafström, I., Ahlmén, M. and Svensson, B. (2007) Sex: A Major Predictor of Remission in Early Rheumatoid Arthritis? Annals of the Rheumatic Diseases, 66, 46-52. https://doi.org/10.1136/ard.2006.056937 
[27] Tengstrand, B., Ahlmén, M. and Hafstrom, I. (2004) The Influence of Sex on Rheumatoid Arthritis: A Prospective Study of Onset and Outcome after 2 Years. The Journal of Rheumatology, 31, 214-222.

[28] Symmons, D.P. (2002) Epidemiology of Rheumatoid Arthritis: Determinants of Onset, Persistence and Outcome. Best Practice \& Research Clinical Rheumatology, 16, 707-722. https://doi.org/10.1053/berh.2002.0257

[29] Kuiper, S.A., van Gestel, A.M., Swinkels, H.L., de Boo, T.M., Da Silva, J.A. and Van Riel, P.L. (2001) Influence of Sex, Age, and Menopausal State on the Course of Early Rheumatoid Arthritis. The Journal of Rheumatology, 28, 1809-1816.

[30] Da Silva, J.A. and Hall, G.M. (1992) The Effects of Gender and Sex Hormones on Outcome in Rheumatoid Arthritis. Bailliere's Clinical Rheumatology, 6, 196-219.

Submit or recommend next manuscript to OALib Journal and we will provide best service for you:

- Publication frequency: Monthly

- 9 subject areas of science, technology and medicine

- Fair and rigorous peer-review system

- Fast publication process

- Article promotion in various social networking sites (LinkedIn, Facebook, Twitter, etc.)

- Maximum dissemination of your research work

Submit Your Paper Online: Click Here to Submit

Or Contact service@oalib.com 